\title{
Inverse $\mathbf{T}$ incision provides improved accessibility to the upper mediastinum
}

\author{
Gabriel Mihai Marta, MD, Clemens Aigner, MD, and Walter Klepetko, MD, Vienna, Austria
}

$\mathrm{T}$ he choice of the appropriate incision for a thoracic surgical procedure is crucial for a successful operation and a satisfying postoperative functional result. Especially in oncologic surgery of advanced mediastinal tumors, the close contact to vital structures demands an optimal surgical field. This report presents an innovative new access as an alternative to the variety of already existing thoracic incisions.

\section{Clinical Summary}

A 59-year-old woman presented with exertional dyspnea and orthopnea and pronounced congestion of the jugular veins. Chest $\mathrm{x}$-ray film showed a mediastinal widening. Computed tomography of the thorax revealed an anterior mediastinal mass with a diameter of $15.8 \times 7.6 \mathrm{~cm}$, with close contact to all major vessels and structures of the upper mediastinum and extension on both sides to the area of the phrenic nerves. However, radiologically, no signs of proved infiltration of vital structures were detected (Figure 1). The pulmonary function test revealed a moderate obstructive disease with a forced vital capacity of $2.19 \mathrm{~L}(68.1 \%)$ and a forced expiratory volume in 1 second of $1.53 \mathrm{~L}(59.4 \%)$. The histologic examination of tumor samples obtained by means of computed tomography-guided biopsy revealed the presence of a malignant mesenchymal fibrous tumor. Further staging examinations excluded any metastatic disease.

The patient underwent 2 cycles of induction chemotherapy with ifosfamide and epirubicin, which did not result in reduction of the tumor size.

The decision was therefore made to offer the patient a surgical resection of the mass.

During planning of the operative procedure, it became obvious that because of the extension of the tumor and its close relationship to the vital mediastinal structures, standard approaches, such as median sternotomy or transverse thoracosternotomy (clamshell or crossbow incision), ${ }^{1}$ would not allow equally good exposure of all anterior and supra-aortic mediastinal structures or sufficient access to the lateral portions of the mediastinal mass. Therefore a com-

\footnotetext{
From the Department of Cardio-Thoracic Surgery, University Hospital of Vienna, Vienna, Austria.

Received for publication Jan 27, 2004; revisions received March 26, 2004; accepted for publication April 6, 2004.

Address for reprints: Walter Klepetko, MD, University Hospital of Vienna, Department of Cardio-Thoracic Surgery, Waehringer Guertel 18-20, 1090 Vienna, Austria (E-mail: walter.klepetko@meduniwien.ac.at).

J Thorac Cardiovasc Surg 2005;129:221-3

$0022-5223 / \$ 30.00$

Copyright (C) 2005 by The American Association for Thoracic Surgery doi:10.1016/j.jtcvs.2004.04.036
}
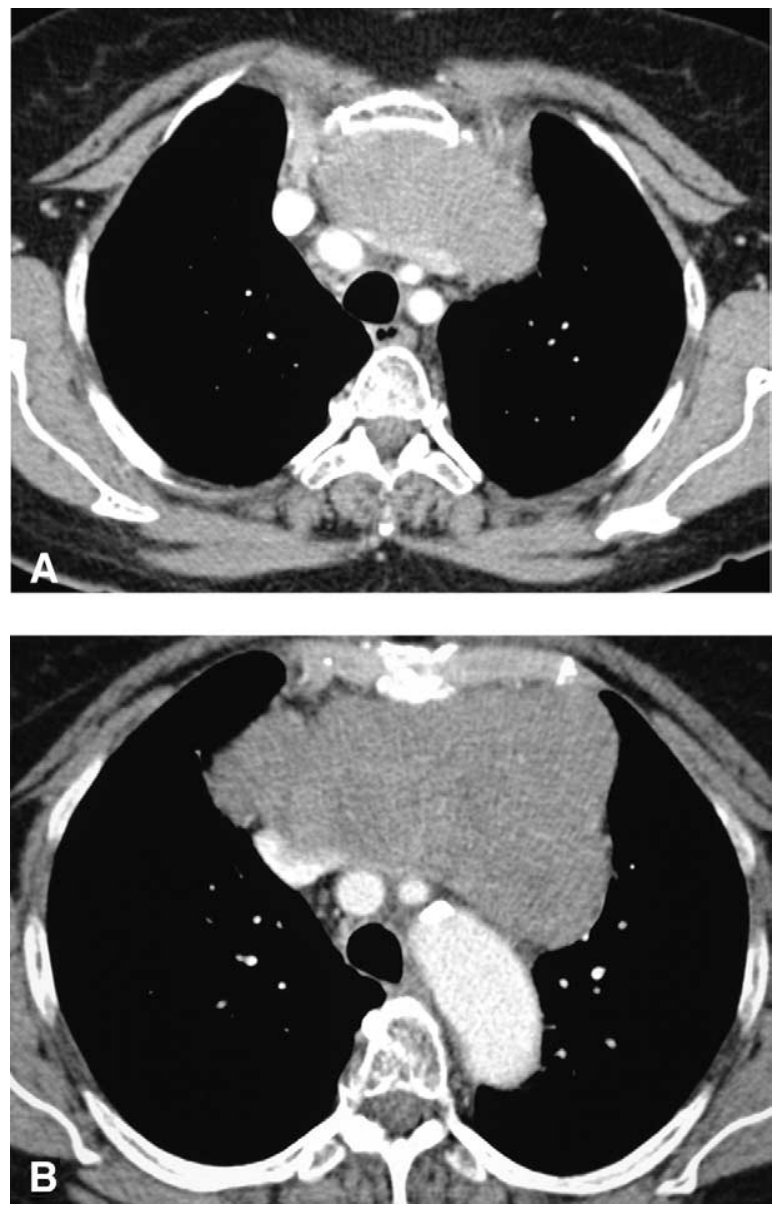

Figure 1. Preoperative computed tomographic image of the thorax: anterior mediastinal mass with a diameter of $15.8 \times 7.6 \mathrm{~cm}$ and close contact to the structures of the upper mediastinum. Radiologically, no signs of infiltration of vital structures were proved.

bination of these 2 standard surgical incisions, transverse thoracosternotomy (clamshell or crossbow incision) at the level of the third intercostal space combined with a partial proximal median sternotomy, was performed (Figure 2).

The intraoperative view revealed the tumor mass, with a welldefined surface, sharply bounded margins, and multiple pronounced humps, filling the upper mediastinum and expanding laterally toward the 2 hemithoraces and evidently compressing the mediastinal structures and the lungs, respectively (Figure 3, A).

Through the large and excellent access, the resectability of the tumoral mass was confirmed, and the dissection of the tumor, beginning at the anterior pericardium, was started. The pericar- 


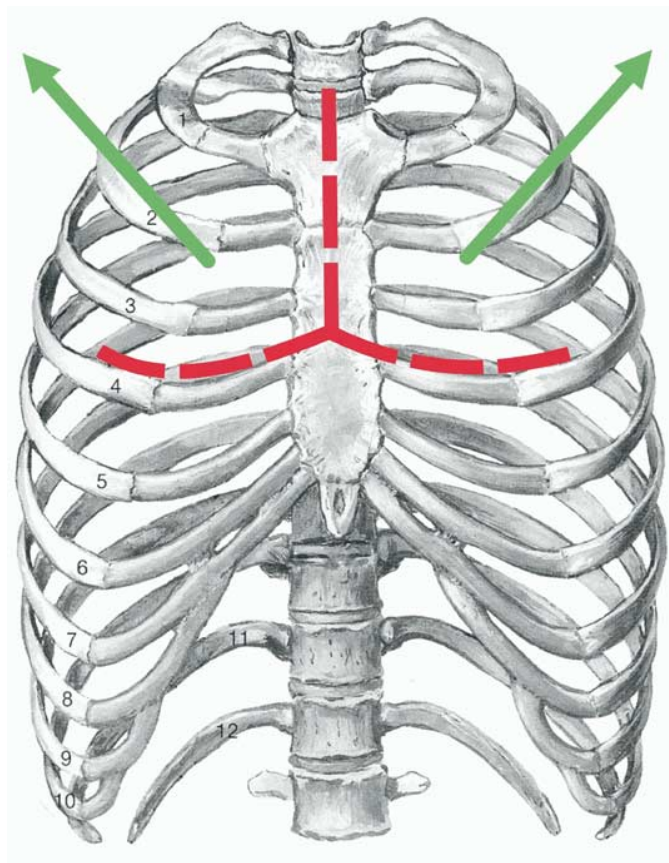

Figure 2. Inverse T incision: transverse thoracosternotomy (clamshell or crossbow incision) at the level of the third intercostal space combined with a partial proximal median sternotomy.

dium was partially resected in its cranial part, followed by bilateral preparation of the pulmonary hilar structures. Both phrenic nerves, as well as the recurrent nerve on the left side, were successfully separated from the tumor capsule and preserved. The tumor was then completely separated from the aortic arch, vagus nerve, vena cava superior, and the vessels of the superior mediastinum. Finally, after ligature of several small arterial and venous vessels, the specimen was removed en bloc (Figure 3, B). For oncologic reasons, an extended mediastinal lymphadenectomy was added.

Wire cerclage was used for closure of the median sternotomy, and polyglactin 910 (Vicryl; Ethicon, Inc, Somerville, NJ), as well as enforced polydioxanone (Ethicon) sutures, were used for the bilateral thoracotomy, respectively.

The patient was extubated in the recovery room 2 hours after the operation. The drainage tubes were removed 48 hours after the operation, and the patient was discharged from the hospital on the 13th postoperative day, without any postoperative complications.

During a further 4-month follow-up period, the patient remained free of any symptoms and recovered completely. Clinically, no evidence of wound-healing disturbances or thoracic wall instability was detected.

Lung function test results improved significantly toward a postoperative maximum forced vital capacity of $2.58 \mathrm{~L}(80.1 \%)$ versus $2.19 \mathrm{~L}(68.1 \%)$ preoperatively and a maximum forced expiratory volume in 1 second of $1.81 \mathrm{~L}(70.6 \%)$ versus $1.53 \mathrm{~L}$ $(59.4 \%)$ before the operation.

The final histologic study revealed an atypical fibrous tumor with an unusually high mitotic activity, which was not considered to be malignant and was proved to be fully resected within normal tissue (R0). All dissected lymph node stations were free of tumor.
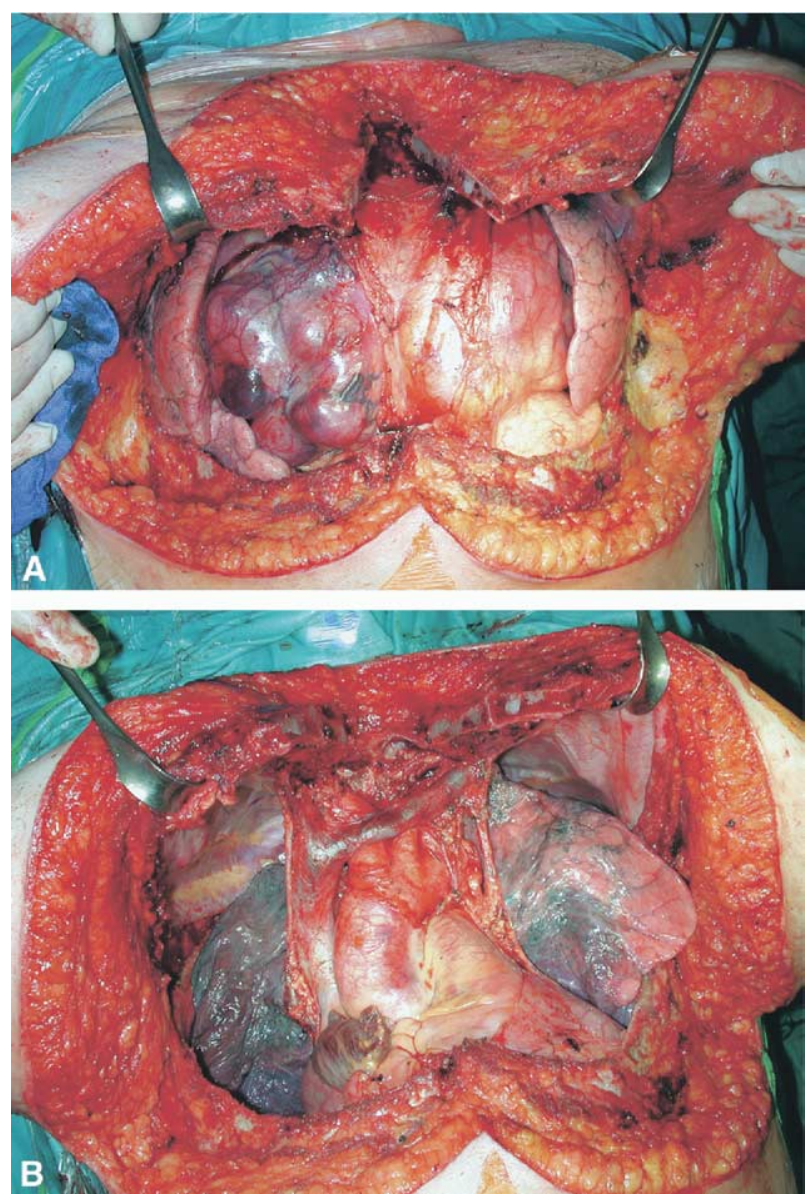

Figure 3. Macroscopic view inside the surgical field: $A$, the site primary to resection; $B$, the site after resection.

\section{Discussion}

A variety of surgical approaches for treatment of complex intrathoracic diseases have been described. Standard incisions include median sternotomy (Milton 1897), standard and extended (Paulson) posterolateral thoracotomy, and anterior and anterolateral thoracotomy. For specific upper mediastinal pathologies, a transaxillary minithoracotomy ${ }^{2}$ or a transcervical approach ${ }^{3}$ can be used, whereas clamshell ${ }^{4}$ and hemiclamshell incision ${ }^{5}$ provide more extensive access to the anterior mediastinum.

However, in rare cases even this existing large reserve of different approaches does not provide sufficient access. The case described herein made it necessary to create a new surgical approach to successfully remove the tumor mass.

The proposed inverse $\mathrm{T}$ incision has not been described in the literature yet and therefore represents a completely new approach. It provides excellent access to the upper mediastinum, as well as to both pulmonary hili, and thus allows an effective dissection virtually in the entire upper third of the thoracic cavity. Additional advantages of the incision are the preservation of the stability and functionality of the sternocostal arch, which facilitates a rapid postoperative respiratory rehabilitation. 
Potential disadvantages of the technique could be wound-healing disturbances, which were not observed in this particular case.

Although the use of this new technique should remain limited to selected cases, it represents a valuable alternative to the already existing spectrum of thoracic incisions.

\section{References}

1. Shields TM, LoCicero J, Ponn RB. General thoracic surgery. 5th ed. Philadelphia: Lippincott Williams \& Wilkins; 2000.
2. Becker RM, Munro DD. Transaxillary minithoracotomy: the optimal approach for certain pulmonary and mediastinal lesions. Ann Thorac Surg. 1976;22:254-9.

3. Cooper JD, Al-Jilaihawa AN, Pearson FG, Humphrey JG, Humphrey HE. An improved technique to facilitate transcervical thymectomy for myasthenia gravis. Ann Thorac Surg. 1988;45(3):242-7.

4. Kaiser LR, Pasque MK, Trulock EP, Low DE, Dresler CM, Cooper JD. Bilateral sequential lung transplantation: the procedure of choice for double-lung replacement. Ann Thorac Surg. 1991;52(3):438-46.

5. Korst RJ, Burt ME. Cervicothoracic tumors: results of resection by the "hemi-clamshell" approach. $J$ Thorac Cardiovasc Surg. 1998;115(2):286-94

\title{
Repair of acute postinfarction ventricular septal defect by endocardial patch exclusion through the aortic valve orifice
}

\author{
Angelo A. Vlessis, MD, PhD, and Timothy Hanlon, MD, Bend, Ore
}

T

he repair of acute postinfarction ventricular septal defects (VSDs) remains a contemporary challenge for cardiac surgeons. The treatment of this devastating condition has evolved considerably during the past 2 decades. Initial experiences with immediate operative intervention in the 1970s were dreadful, and there was therefore little enthusiasm for acute surgical intervention. In the early 1980s, delayed repair was an accepted practice. ${ }^{1}$ Patients were stabilized with an intraaortic balloon pump for 3 weeks before an attempt at surgical intervention. Those patients who survived the waiting period understandably had better surgical outcomes. Regrettably, patients frequently died or became more unstable during the waiting period. This prompted some surgeons to reconsider earlier repair. ${ }^{2}$ Patch replacement of the ventricular septum evolved as the preferred method of repair. Mortality remained high, however, and studies from the late 1980s and early 1990s reported mortality rates of $40 \%$ to $70 \%{ }^{3,4}$ In 1995 David and colleagues ${ }^{5}$ introduced the idea of left ventricular endocardial patch exclusion of the infarcted ventricular septum. The operative mortality reported with this new approach was an inspiring 14\%. Many surgical groups, including our own, have adopted the technique with equivalent success. Our case report describes the technique of endocardial patch exclusion of an acute postinfarction VSD through the aortic valve orifice, thereby avoiding ventriculotomy and the subsequent

From the Heart Institute of the Cascades, Bend, Ore.

Received for publication March 17, 2004; accepted for publication April 20, 2004.

Address for reprints: Angelo A. Vlessis, MD, PhD, Cardiothoracic Surgeons, PC, 2705 NE Conners Ave, Suite A, Bend, OR 97701 (E-mail: vlessis@bendcable.com).

J Thorac Cardiovasc Surg 2005;129:223-4

$0022-5223 / \$ 30.00$

Copyright $\odot 2005$ by The American Association for Thoracic Surgery doi:10.1016/j.jtcvs.2004.04.038

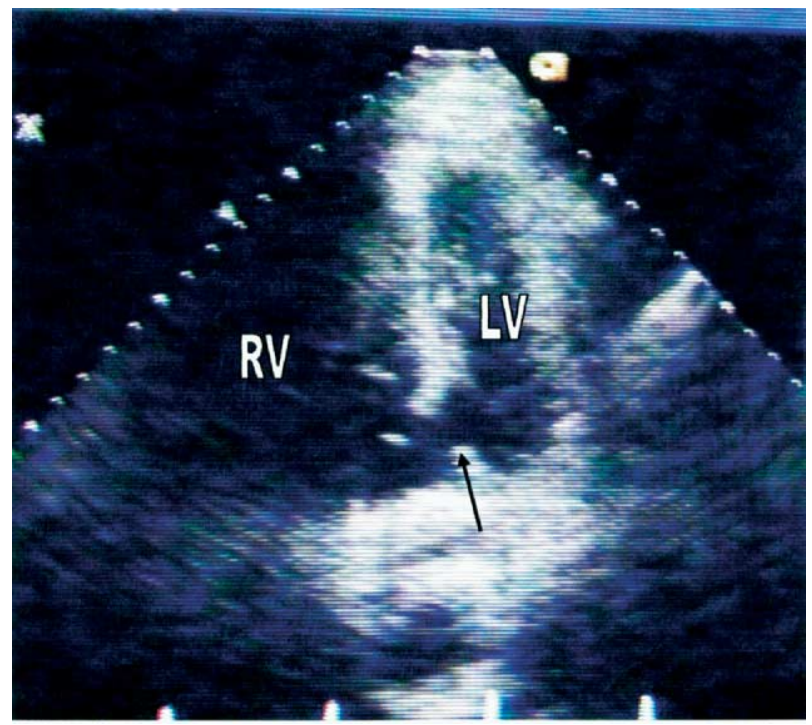

Figure 1. Preoperative echocardiogram demonstrating large acute VSD (black arrow). RV, Right ventricle; $L V$, left ventricle.

right ventricular dysfunction that often leads to death or prolongation of in-hospital recovery.

\section{Clinical Summary}

A 66-year-old man came to his primary care physician with a report of 8 to 10 days of epigastric discomfort followed by acute onset of shortness of breath and orthopnea. A heart murmur was detected, and the patient was referred urgently for cardiologic evaluation. A chest radiograph showed congestive heart failure with bilateral pleural effusions. Laboratory studies revealed renal insufficiency. A transthoracic echocardiogram showed a $2.1 \mathrm{~cm}$ VSD in the inferobasilar septum, right ventricular dysfunction, pulmonary hypertension, and an akinetic inferior myocardium 